\title{
Fenologia de Cedrela fissilis Vell. (Meliaceae) na região rural de Itirapina, SP, Brasil
}

\author{
Débora Leonardo dos Santos $^{1}$ e Massanori Takaki ${ }^{2,3}$
}

Recebido em 04/08/2003. Aceito em 18/02/2005

\begin{abstract}
RESUMO - (Fenologia de Cedrela fissilis Vell. (Meliaceae) na região rural de Itirapina, SP, Brasil). A fenologia de queda de folhas, brotação, floração e frutificação de Cedrela fissilis Vell. foi estudada de setembro/1999 a novembro/2001 na zona rural do Município de Itirapina, SP. Foram observados, a cada 14 dias, 10 indivíduos que apresentaram comportamento fenológico sazonal, com ocorrência seqüencial das fenofases, queda de folhas na estação seca, brotação seguida de floração no início da estação chuvosa, e frutificação longa, com a duração de 11 meses, dispersando as sementes aladas ao final da estação seca. O desfolhamento total durante os meses mais secos do ano caracterizou a espécie como decídua. A floração e frutificação ocorreram em ciclos supra anuais.
\end{abstract}

Palavras-chave: decídua, floração, sazonal, mata secundária, cedro rosa

\begin{abstract}
Phenology of Cedrela fissilis Vellozo (Meliaceae) in Itirapina, São Paulo State, Brazil). The study of phenology of leaf fall, flushing, flowering and fruiting was carried at from September /1999 to November/2001. Ten trees were systematically observed every at 14 days intervals. Leaf fall ocurred at the dry season and flushing and flowering at the beginning of rain season. The fruiting period was long, and dispertion at the end of dry season. Flowering and fruiting not showed an annual cycle, years which massive flowers and fruits was followed by non productive year.
\end{abstract}

Key words : deciduous, flowering, seasonal, secondary forest, cedro rosa

\section{Introdução}

A observação fenológica reúne informações sobre o estabelecimento de espécies, o período de crescimento, reprodução e a disponibilidade de recursos alimentares, que podem estar associadas a mudanças na qualidade e na abundância de recursos, como luz e água (Morellato \& Leitão-Filho 1992). A época em que acontecem os eventos reprodutivos nas plantas é determinante para o sucesso da população, ao assegurar a sobrevivência e o estabelecimento dos indivíduos jovens (Ferraz et al. 1999). A fenologia das espécies é regulada pelas suas características endógenas associadas às variações de clima, além de fatores abióticos e bióticos (Janzen 1967). Algumas plantas iniciam a produção de flores estimuladas pela variação sazonal na irradiação solar (Wright \& van Schaik 1994) e dispersam suas sementes ao final da estação seca e início da chuvosa, o que reduz a mortalidade das plântulas (Frankie et al. 1974; van Schaik et al. 1993).
Florescer sincronizadamente favorece a atração de polinizadores facilitando o fluxo de pólen e a reprodução cruzada (Maquis 1988). Da mesma maneira, a produção sincronizada de frutos pode saciar os predadores de sementes e aumentar a atratividade de frugívoros necessários à sua dispersão das sementes (Janzen 1971). Nos trópicos, fatores climáticos e interações entre espécies estão freqüentemente associados com a sazonalidade dos eventos fenológicos das plantas, tanto ao nível de comunidade (Frankie et al. 1974; Morellato et al. 2000; Justiniano \& Fredericksen 2000; Bencke \& Morellato 2002), quanto de espécie (Gomez \& Fournier 1996; Almeida \& Alves 2000; Pedroni et al. 2002)

Quanto aos padrões de brotamento e queda foliar, as espécies podem ser classificadas, como: Decídua espécie com queda e produção de folhas concentradas em determinada época, ficando por um período de tempo quase ou totalmente sem folhas; Semidecídua espécie com um período de maior intensidade de queda

\footnotetext{
I Universidade Estadual do Sudoeste da Bahia, Departamento de Ciências Naturais, Estrada do Bem-Querer km 04, CEP 45083-900, Vitória da Conquista, BA, Brasil

2 Universidade Estadual Paulista, Departamento de Botânica, C. Postal 199, CEP 13506-900, Rio Claro, SP, Brasil

3 Autor para correspondência: massa@rc.unesp.br
} 
de folhas, não ficando muito concentrado, e totalmente sem folhas, apresentando padrões variados de produção foliar; e Perenifólia - espécie que produz continuamente, ou de forma intermitente, uma pequena quantidade de folhas novas e não apresenta queda de folhas concentrada numa determinada época do ano, sendo esta, em geral, imperceptível ou pouco visível (Morellato et al. 1989).

O cedro rosa, Cedrela fissilis Vell. (Meliaceae), está entre as mais importantes madeiras de interesse econômico do Brasil, considerada espécie rara devido à sua distribuição escassa dentro da floresta primária; no entanto, apresenta comportamento muito agressivo em matas secundárias, por isso é encontrada freqüentemente em pastos abandonados e fragmentos de mata em propriedades rurais (Carvalho 1994).

O cedro rosa apresenta atualmente distribuição rarefeita e esparsa, sendo que os melhores fenótipos para a utilização madeireira já desapareceram, e restaram os indivíduos com pior forma silvicultural, e a espécie como um todo está sofrendo uma severa erosão genética pela perda de muitas populações e indivíduos (F.B. Gandara, dados não publicados).

Para F.B. Gandara (dados não publicados), Cedrela fissilis é bastante efetiva na regeneração de áreas abandonadas, apresentando alta densidade de indivíduos, podendo, no entanto, essas populações estarem geneticamente degradadas. Segundo Carvalho (1994) a alta densidade de indivíduos pode favorecer o ataque da broca-do-cedro (Hypsipyla grandella Zeller, Lepidoptera: Pyralidae) e o valor comercial ficar comprometido, pois as árvores ficam deformadas.

De um modo geral as informações fenológicas são importantes do ponto de vista botânico e ecológico, e necessárias para apoiarem outros estudos, como os de produção e tecnologia de sementes, indicando por exemplo a melhor época de colheita e de plantio para cada espécie, sendo portanto uma ferramenta indispensável para programas de manejo e de recomposição florestal. O estudo de Cedrela fissilis em ambientes que sofreram a ação antrópica fornecem informações importantes sobre as mudanças de comportamento da espécie e pode oferecer ao proprietário rural uma fonte de renda alternativa, como a comercialização de sementes, que poderá estimular a manutenção das espécies arbóreas em sua propriedade.

O trabalho teve como objetivo a determinação do padrão fenológico de uma população de Cedrela fissilis localizada na zona rural do município de Itirapina, SP e a correlação das fenofases com os fatores climáticos.

\section{Material e métodos}

O estudo da fenologia de Cedrela fissilis foi realizado em indivíduos localizados no Sítio Serrinha, propriedade particular localizada no Município de Itirapina, Estado de São Paulo $\left(22^{\circ} 15^{\prime} \mathrm{S}, 47^{\circ} 42^{\prime} \mathrm{W}\right.$, 771 m s.m.). A vegetação característica da região é Floresta Estacional Semidecidual, encontrada em locais de difícil acesso, nos quais não é possível a exploração agrícola ou em propriedades abandonadas onde aparecem as matas secundárias. $\mathrm{O}$ clima da região é do tipo Cwa (Köppen) e o solo do tipo latossolo vermelho.

Foram marcados com plaquetas de metal inoxidável numeradas, 10 indivíduos de Cedrela fissilis, segundo a ordem de aparecimento (Fournier 1976). No início das observações os indivíduos foram medidos quanto à altura e ao diâmetro a 1,30 m de altura do solo (DAP). Para as observações dos parâmetros fenológicos foi utilizado um binóculo Travelite III 9×25 CF (Nikon, Japan).

Os parâmetros fenológicos observados foram: queda foliar - período em que as folhas mudam de cor e caem com facilidade, ocasionando espaços vazios (falhas) na copa ou em ramos; brotação - período que se inicia com o surgimento de pequenas folhas, de coloração marrom nos ápices dos ramos, e termina quando as folhas adquirem coloração verde; botões período que se inicia quando, na região apical dos ramos, aparecem gemas reprodutivas e termina quando as flores iniciam a abertura (antese); flores - período em que a árvore apresenta flores em antese; fruto verde - inicia quando é possível visualizar os frutículos após a fertilização das flores e termina com o início da abertura espontânea dos frutos; fruto maduro - inicia com a abertura dos frutos e termina com a dispersão das sementes. As observações foram a cada duas semanas, no período de 1/setembro/1999 a 30/novembro/2001, seguindo as categorias de quantificação de Fournier (1974), que enquadra o evento em quatro classes de percentagem de ocorrência da fenofase em relação à copa, com amplitudes de $25 \%$ cada uma.

Calculando-se os valores médios mensais para cada fenofase, foram elaborados fenogramas mostrando a evolução de cada parâmetro, e sua relação com os dados climáticos locais durante o período de observações. Os dados climáticos foram obtidos no posto meteorológico do Parque Florestal Saligna, Fazenda Siriema, Município de Itirapina, pertencente à Empresa Ripasa de Papel e Celulose $\left(22^{\circ} 15^{\prime} \mathrm{S}\right.$, 
$47^{\circ} 52^{\prime} \mathrm{W}, 765 \mathrm{~m}$ s.m.), durante o período de 1/junho/1999 a 30/novembro/2001. Foi calculada a média mensal dos valores diários para temperaturas máxima, média e mínima, pluviosidade e umidade relativa do ar.

As variáveis utilizadas para descrever os tipos de fenofases seguiram as recomendações de Morellato et al.(1989): Periodicidade - repetibilidade e regularidade do ciclo fenológico; Freqüência - número de ciclos por unidade de tempo, expresso como frações ou múltiplos de ano (sub-anual = mais de um ciclo por ano; anual = um ciclo por ano; ou supra-anual $=$ menos de um ciclo por ano); Duração - período de tempo que a planta permanece em uma dada fase; Época - é o dia, mês ou estação do ano em que o evento ocorre; Amplitude - intensidade de atividade ou nível de resposta, como por exemplo o número de flores em uma árvore; Sincronia - proporção de indivíduos amostrados que estão manifestando determinado evento fenológico $(<20 \%$ assincrônico; $20-60 \%$ pouco sincrônico; $>60 \%$ sincronia alta, Bencke \& Morellato (2002).

Para verificar a existência da ação dos fatores climáticos com os eventos fenológicos, foi realizada a análise de correlação de Spearman $\left(r_{s}\right)$ (Siegel 1975). Esta análise foi realizada correlacionando-se os eventos fenológicos com os dados climáticos do mês, do primeiro, segundo ou terceiro mês anteriores do evento fenológico, conforme descrito por Ferraz et al. (1999).

\section{Resultados e discussão}

Os indivíduos de Cedrela fissilis amostrados apresentaram entre 6 e $18 \mathrm{~m}$ alt., sendo a média $12,8 \pm 3,32 \mathrm{~m}$ e entre $0,20-0,80 \mathrm{~m}$ de DAP, sendo a média de $0,58 \pm 0,17 \mathrm{~m}$. Das 10 árvores utilizadas para o acompanhamento fenológico apenas uma não apresentou fase reprodutiva durante o período de estudo, podendo ser considerada jovem pois apresentou o menor tamanho, com seis metros de altura e $0,20 \mathrm{~m}$ de DAP, os demais indivíduos apresentaram altura acima de $10 \mathrm{~m}$ e DAP superior a $0,45 \mathrm{~m}$. O cedro, em mata primária, ocorre com indivíduos esparsos e suas copas pertencem ao estrato superior, sendo que podem atingir até $40 \mathrm{~m}$ alt., $2 \mathrm{~m}$ de DAP e fuste com até $15 \mathrm{~m}$ compr.; já em matas secundarias são mais numerosas e muitas delas se deformam ou morrem devido ao ataque da broca do cedro (Carvalho 1994). Segundo o mesmo autor, a frequiência do cedro nas florestas do sul do Brasil, varia de uma a três árvores por hectare, considerando ser esta baixa densidade uma estratégia encontrada pela espécie para evitar o ataque da broca do cedro; por sua vez F.B. Gandara (dados não publicados) encontrou densidade menor ainda, de 0,13 árvore por hectare em mata primária.

$\mathrm{Na}$ região rural de Itirapina, SP, as árvores de Cedrela fissilis apresentaram comportamento fenológico sazonal (Fig. 1). A queda foliar apresentou padrão decíduo, permanecendo completamente sem folhas durante a estação seca. A queda das folhas iniciou-se nos meses de dezembro1999 e janeiro/2001 em período com precipitação elevada, aumentando de intensidade com a diminuição da precipitação e da temperatura, e terminou em setembro/2000 e agosto/2001, coincidindo com o inicio da estação chuvosa, sendo que o pico de atividade ocorreu nos meses de junho e julho/2000 e maio e junho/2001. A sincronização entre os indivíduos amostrados foi elevada (Tab. 1) e a periodicidade do evento foi anual (Fig. 2). A queda de folhas apresentou correlação negativa significativa com a precipitação e a temperatura média durante o pico do evento, no entanto, no segundo e terceiro meses anteriores, observou-se correlação positiva com a precipitação, a umidade relativa e a temperatura média (Tab. 2). Isso sugere que a queda foliar está relacionada com fatores climáticos anteriores ao evento, ou seja, a diminuição da precipitação, da umidade relativa e da temperatura levou a um aumento gradual na perda de folhas. Talora e Morellato (2000) também encontraram correlação negativa entre pluviosidade e temperatura média e a queda foliar em floresta de planície litorânea na região de Ubatuba. Para uma população de Copaifera langsdorffii Desf. localizada em uma floresta semidecídua, a queda de folhas foi regular e sincronizada e mostrou estar fortemente correlacionada com a diminuição da pluviosidade, sendo este o fator desencadeador da perda de folhas (Pedroni et al. 2002).

A queda gradual de folhas durante o ano pode ser conseqüência da senescência natural ou também uma adaptação da espécie para economia de água; assim,

Tabela 1. Grau de sincronia por fenofase, em percentagem de indivíduos, estimado no período de máxima atividade das fenofases de Cedrela fissilis Vell., na região rural de Itirapina, São Paulo, Brasil

\begin{tabular}{lcccccc}
\hline Ano & \multicolumn{6}{c}{ Fenofases } \\
\cline { 2 - 7 } & Botão & Flor & $\begin{array}{c}\text { Fruto } \\
\text { verde }\end{array}$ & $\begin{array}{c}\text { Fruto } \\
\text { maduro }\end{array}$ & $\begin{array}{c}\text { Queda } \\
\text { folhas }\end{array}$ & Brotamento \\
\hline 1999 & 90 & 90 & 90 & 90 & 100 & 100 \\
2000 & 30 & 30 & 30 & 30 & 100 & 100 \\
2001 & 90 & 90 & 90 & - & 100 & 100 \\
\hline
\end{tabular}


com início da seca, quando as chuvas cessaram completamente, as árvores perderam todas as folhas. Borchert (1980) trabalhando com a fenologia de populações de Erythrina poeppigiana O.F. Cook. em São José, na Costa Rica, verificaram que algumas dessas populações apresentaram padrões fenológicos assincrônicos, sugerindo que ocorreu um forte controle endógeno no desenvolvimento das árvores com dois ciclos de muda de folhas durante o ano, que pareceram primariamente ser resultado da senescência foliar. Árvores de maior porte localizadas em áreas com déficit hídrico perderam as folhas no inicio da seca;
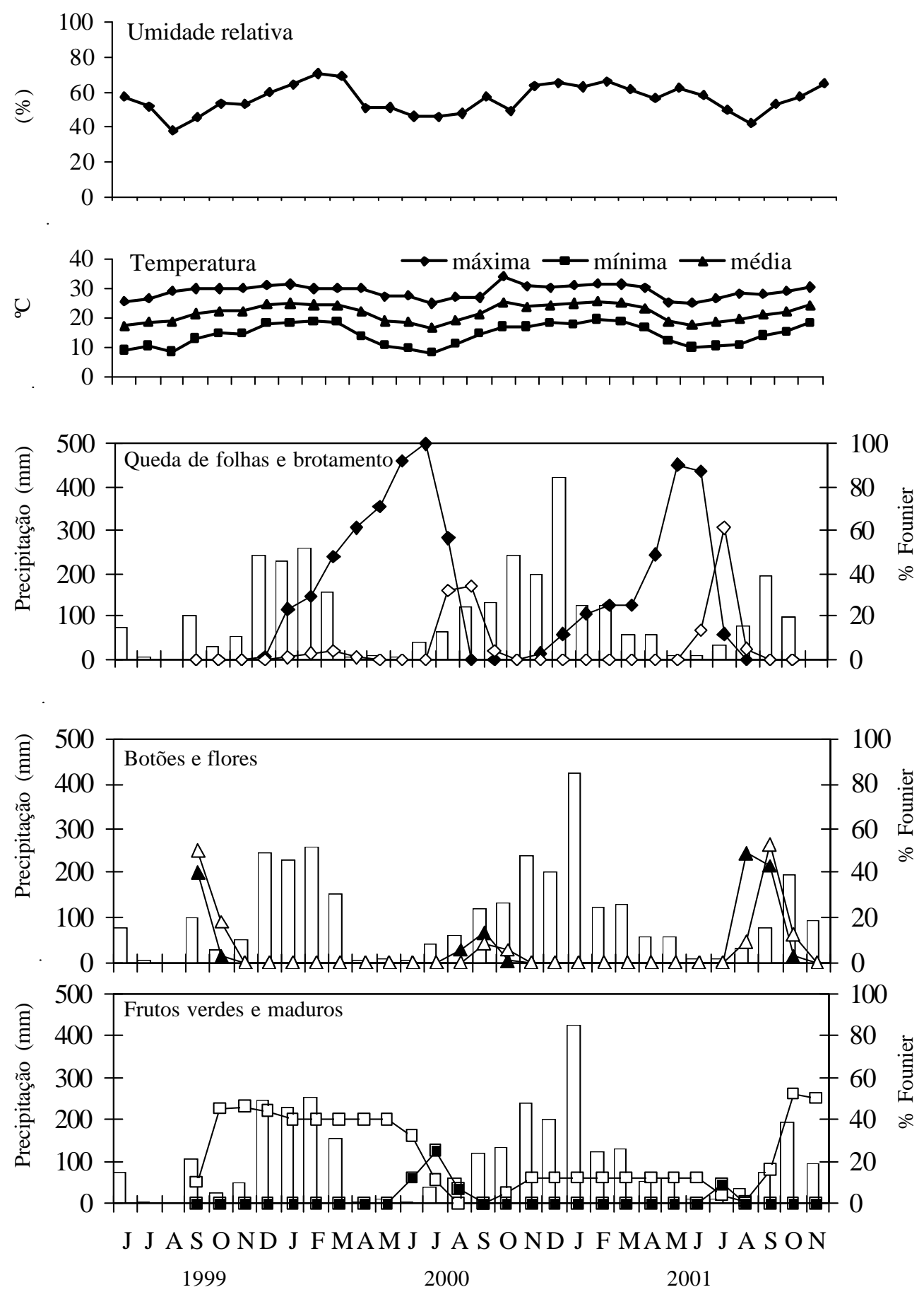

Figura 1. Padrão fenológico de Cedrela fissilis Vell., em média do índice de Fournier $(\mathrm{n}=10)$ e as condições climáticas, durante o período de estudo na região rural de Itirapina, SP, Brasil $\left(22^{\circ} 15^{\prime} \mathrm{S}, 47^{\circ} 42^{\prime} \mathrm{W}, 771 \mathrm{~m} \mathrm{s.m}\right)$. Convenções: $\bullet=$ queda de folhas; $\diamond=$ brotamento; $\triangle$ = botão; $\boldsymbol{\Lambda}$ = flor; $\square$ = fruto verde; $\mathbf{\square}$ = fruto maduro; barras = precipitação mensal. 


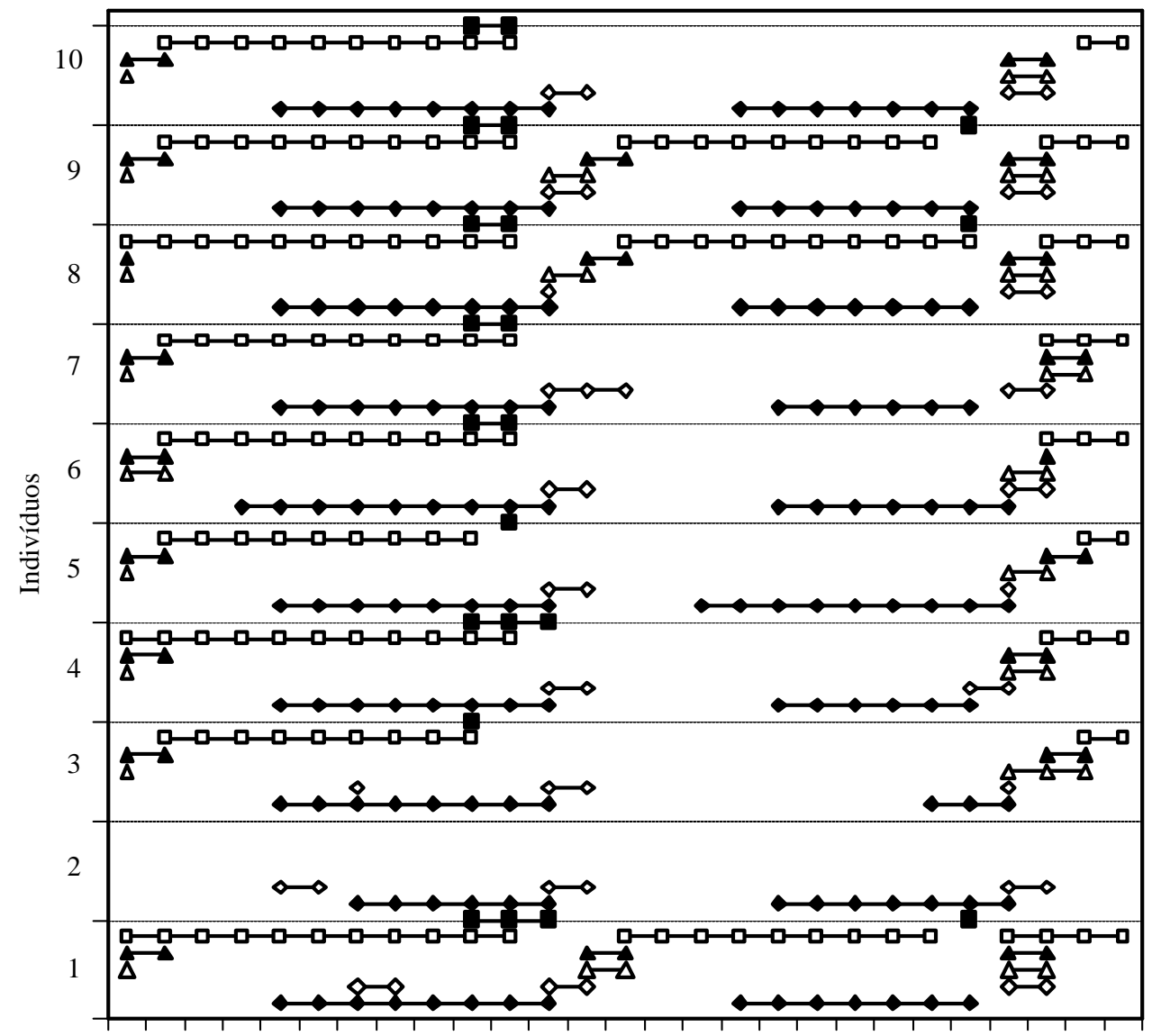

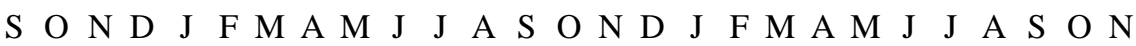

$19992000 \quad 2001$

Figura 2. Eventos fenológicos de cada indivíduo da população de Cedrela fissilis Vell. estudados na região rural de Itirapina, SP, Brasil ( $22^{\circ} 15^{\prime} \mathrm{S}, 47^{\circ} 42^{\prime} \mathrm{W}, 771 \mathrm{~m} \mathrm{s.m}$.). Convenções: $\bullet=$ queda de folhas; $\diamond=$ brotamento; $\Delta=$ botão; $\boldsymbol{\Delta}=$ flor; $\square=$ fruto verde; $\boldsymbol{\square}=$ fruto maduro; barras = precipitação mensal.

Tabela 2. Valores da análise de correlação de Spearman $\left(r_{s}\right)$ entre os fatores climáticos (precipitação media mensal, umidade relativa media mensal e temperatura media mensal) de 0, mês de ocorrência do evento; 1,2 e 3 meses anteriores ao mês do evento fenológico de Cedrela fissilis Vell. (queda de folhas, brotação, botão, flor, fruto verde e fruto maduro). * o teste não apresentou correlação significativa para $\mathrm{P}<0,05$.

\begin{tabular}{|c|c|c|c|c|c|c|c|}
\hline & Meses & Queda folhas & Brotação & Botão & Flor & Fruto verde & Fruto maduro \\
\hline \multirow[t]{4}{*}{ Precipitação } & 0 & $-0,43$ & $*$ & $*$ & $*$ & $*$ & $-0,41$ \\
\hline & 1 & $*$ & $*$ & $-0,37$ & $*$ & $*$ & $-0,41$ \\
\hline & 2 & $*$ & $*$ & $-0,64$ & $-0,56$ & $*$ & $*$ \\
\hline & 3 & 0,44 & $*$ & $-0,49$ & $-0,44$ & $*$ & $*$ \\
\hline \multirow[t]{4}{*}{ Umidade relativa } & 0 & $*$ & $*$ & $-0,49$ & $-0,39$ & $*$ & $*$ \\
\hline & 1 & $*$ & $*$ & $-0,65$ & $-0,57$ & $*$ & $*$ \\
\hline & 2 & 0,44 & $*$ & $-0,54$ & $-0,52$ & $*$ & $*$ \\
\hline & 3 & 0,59 & $*$ & $*$ & $*$ & $*$ & $*$ \\
\hline \multirow[t]{4}{*}{ Temperatura média } & 0 & $-0,39$ & $*$ & $*$ & $*$ & $*$ & $-0,63$ \\
\hline & 1 & $*$ & $*$ & $-0,56$ & -0.42 & $*$ & $-0,44$ \\
\hline & 2 & 0,45 & $*$ & $-0,77$ & $-0,68$ & $*$ & $*$ \\
\hline & 3 & 0,75 & * & $-0,74$ & $-0,75$ & $*$ & $*$ \\
\hline
\end{tabular}


enquanto que, árvores pequenas e localizadas em locais úmidos desfolharam após três meses do início da mesma estação. O aumento do estresse hídrico atmosférico causado pelo aumento da altitude, levou a uma transição de hábito perene para decíduo.

O brotamento de folhas novas em Cedrela fissilis teve atividade concentrada entre julho e outubro/2000 e junho e setembro/2001, tendo o seu início coincidente com as primeiras chuvas depois do período de estiagem. O pico de intensidade foi em agosto/2000 e 2001 (Fig 1). O sincronismo entre os indivíduos amostrados foi elevado (Tab. 1) e a periodicidade foi anual (Fig. 2). Nesta espécie os brotos foliares recém surgidos são castanho avermelhado, tornando-se depois verde claro e quando estão na fase de folha madura são verde intenso, permanecendo desta cor até a senescência, que é percebida pela cor amarela avermelhada dos folíolos. Essa fenofase não apresentou correlação significativa com nenhum dos fatores climáticos estudados: temperatura e precipitação (Tab. 2). A perda total das folhas durante o período mais seco do ano pode estar relacionada com a economia de água ocasionando a diminuição das trocas gasosas incluindo a de água entre as folhas e o ambiente. Muitas árvores de climas com secas sazonais perdem completamente as folhas, e em conseqüência do alívio de estresse hídrico brotam ainda durante a estação seca. Por outro lado, em outras espécies tropicais, a reidratação das árvores, que acontece após a queda das folhas, não induz o brotamento, e as árvores permanecem dormentes durante um certo período. Em Cedrela fissilis, as árvores permaneceram sem folhas durante o período mais seco e frio do ano, comportamento igual foi encontrado para espécies de Cedrela por Reich \& Borchert (1984) em floresta tropical seca da Costa Rica e por Ferraz et al. (1999) em um fragmento de mata na cidade de São Paulo. A queda de folhas e o brotamento foram os eventos mais regulares e sincronizados entre os indivíduos da população de cedro estudada.

O sincronismo do brotamento durante um determinado período tem sido sugerido como uma estratégia para evitar a emissão de folhas novas durante as estações desfavoráveis (van Schaik et al. 1993). E também, segundo Pedroni et al. (2002), a produção sincronizada de folhas afeta a comunidade de herbívoros provocando flutuações em suas populações, por que concentra os recursos alimentares em poucos meses. Assim, folhas produzidas simultaneamente devem sofrer menos danos do que folhas produzidas fora do pico de brotamento, já que com o aumento de disponibilidade de alimento os herbívoros são saciados mais facilmente.

Em setembro/1999, no início do presente estudo, as árvores estavam na fase reprodutiva, apresentando intensa atividade de floração. A fase de botão floral iniciou logo após o período da brotação foliar, quando as folhas já estavam maduras. De acordo com Borchert (1983), o meristema apical de algumas espécies de árvores podem se desenvolver da fase vegetativa para a reprodutiva e essa transição pode ocorrer ontogeneticamente, como por exemplo em Cedrela, Tabebuia e Cordia. Foram observadas a ocorrência de três eventos de floração, o primeiro ocorreu no início das observações em setembro e outubro/1999, o segundo no período de agosto a outubro/2000, e o terceiro de julho a outubro/2001. O pico de atividade da fenofase de botão floral para os 3 eventos ocorreu no mês de setembro (Fig. 1). O sincronismo entre os indivíduos que apresentaram a fenofase foi elevado no primeiro e terceiro evento, e baixo para o segundo evento (Tab. 1). A fenofase de flor ocorreu simultaneamente com a fase de botão, sendo o primeiro evento de setembro e outubro/1999, o segundo de setembro e outubro/2000 e o terceiro de agosto a outubro/2001. Assim, Cedrela fissilis apresentou, nesse estudo, comportamento supra anual para a fase reprodutiva (Fig. 2).

A análise de correlação de Spearman mostrou que as fenofases de botão e flor apresentaram correlações negativas com a temperatura média no primeiro, segundo e terceiro meses anteriores a floração. A precipitação e umidade relativa do ar também se correlacionaram negativamente com as fenofases de botão e flor nos meses anteriores ao evento, mas somente a UR apresentou correlação negativa significativa durante a floração (Tab. 2). Esses resultados mostram a influencia do clima dos meses anteriores à fase reprodutiva regulando a intensidade de produção de sementes das espécies arbóreas, como já observados por outros autores (Ferraz et al. 1999; Pedroni et al. 2002). Por outro lado, Ferraz et al. (1999) obtiveram resultados inversos durante a transição da estação seca para úmida em Cedrela fissilis na mata da Reserva da Cidade Universitária da Universidade de São Paulo, na região metropolitana de São Paulo, onde houve uma forte correlação positiva entre a floração e os fatores climáticos de dois meses anteriores ao evento, assim o aumento da temperatura média e da precipitação induziram a floração. Por outro lado, estas diferenças encontradas para uma mesma espécie sugere que, a interação dos fatores climáticos ou mesmo, como indicado por Pedroni et al. (2002) 
para Copaifera langsdorfii, as interações com dispersores e predadores de sementes podem influenciar os padrões fenológicos em Cedrela fissilis.

Morellato (1990) também relacionou o aumento dos valores dos fatores climáticos como a temperatura, a precipitação e o comprimento do dia com as espécies que florescem nessa época.

O padrão de florescimento apresentado por Cedrela fissilis pode ser considerado, segundo a classificação de Newstrom et al. (1994) como regular, pois a floração sempre ocorreu no mesmo período do ano e supra anual, porque não ocorreu todos os anos em todas as árvores (Fig. 2). Cedrela fissilis floresceu em setembro-outubro, depois do brotamento explosivo.

O tempo de maturação dos frutos foi longo, durando 11 meses, e a fenofase na qual os frutos permaneceram verdes estendeu-se de setembro/1999 a julho/2000 e de setembro/2000 a julho/2001, podendo ser chamada de fase de maturação e crescimento dos frutos (Fig. 1). Uma nova fase de frutificação iniciou em outubro/2001 no final do período de estudo. A sincronia foi alta, a intensidade do evento foi elevada no primeiro e terceiro ano de observação. No segundo ano poucas árvores amostradas apresentaram frutificação e também foi observada queda de frutículos no início da fenofase (Tab. 1 e Fig. 2). O amadurecimento dos frutos iniciou em junho/2000 e 2001, durante a época de seca e se estendeu até agosto/2000 e 2001, quando iniciou a precipitação (Fig. 1, 2). O pico de atividade foi em julho/2000 e 2001 quando a maioria dos frutos estava aberta com dispersão das sementes antes do início do período de chuva. A fenofase de fruto verde não apresentou correlação significativa com nenhum dos fatores climáticos estudados, as fases de frutos maduros e de dispersão das sementes apresentaram correlação negativa com a precipitação e temperatura média durante a ocorrência do evento e no primeiro mês anterior a fenofase (Tab. 2).

Cedrela fissilis apresenta frutos secos e sementes aladas anemocóricas, e dispersou suas sementes na estação seca seguinte a floração. Existe uma forte relação entre a época de produção de frutos, o tipo de fruto (seco ou carnoso) e a síndrome de dispersão das espécies (Frankie et al. 1974; Morellato 1990). Segundo Morellato \& Leitão-Filho (1992), entre espécies que florescem em setembro e outubro, aquelas que possuíam frutos carnosos apresentaram frutos maduros na estação chuvosa e as que apresentaram frutos secos zoocóricos ou anemocóricos frutificaram na estação seca seguinte à floração. A dispersão de sementes em Cedrela fissilis também é favorecida pela sua posição no dossel; e como emergentes na mata podem expor suas sementes ao vento, que são mais fortes durante a estação seca (Justiniano \& Fredericksen 2000).

O ritmo fenológico de Cedrela fissilis em mata secundária apresentou o mesmo padrão encontrado por Ferraz et al. (1999) em um fragmento de mata na região metropolitana de São Paulo, SP. As árvores perderam completamente as folhas no período mais seco do ano, e brotaram intensamente no início das chuvas; a floração ocorreu logo após o amadurecimento das folhas e apresentou padrão supra anual; o período de maturação dos frutos foi longo, permanecendo os frutos verdes nas árvores por 11 meses; e quando a queda de folhas estava bastante acentuada, ocorreu o amadurecimento dos frutos que se tornaram castanho e mais leves e abriram espontaneamente dispersando suas sementes aladas durante a estação seca.

As árvores de cedro rosa estudadas produziram grandes quantidades de sementes a cada dois anos, sendo viável a colheita e revenda dessas sementes. Apesar da importância econômica da espécie, será necessário o estudo do comportamento genético, pois Kageyama \& Gandara (1998) verificaram que o aumento de densidade de Cedrela fissilis de floresta primária para a secundária pode provocar uma estruturação familiar na nova população antrópica; ou seja, parentesco entre os indivíduos mais próximos, levando as gerações seguintes a problemas de endogamia, e suas prováveis implicações negativas de má adaptação da população, com perda de vigor e má reprodução em seus indivíduos.

\section{Agradecimentos}

Os autores agradecem ao $\mathrm{CNPq}$, pela bolsa de estudos do primeiro Autor; ao posto meteorológico do Parque Florestal Saligna, pertencente à empresa RIPASA de Papel e Celulose, que forneceu os dados climáticos; ao proprietário do sítio Serrinha, por permitir a realização desse estudo.

\section{Referência bibliográficas}

Almeida, E.M. \& Alves, M.A.S. 2000. Fenologia de Psychotria nuda e Psychotria brasiliensis (Rubiaceae) em uma área de Floresta Atlântica no Sudoeste do Brasil. Acta Botanica Brasilica 14(3): 335-346.

Bencke, C.S.C. \& Morellato, L.P.C. 2002. Estudo comparativo da fenologia de nove espécies arbóreas em três tipos de floresta atlântica no sudeste do Brasil. Revista Brasileira de Botânica 25(2): 237-248. 
Borchert. R. 1980. Phenology and ecophysiology of tropical trees: Erythrina poeppigiana O.F. Cook. Ecology 61(5): 1065-1074.

Borchert. R. 1983. Phenology and control of flowering in tropical trees. Biotropica 15(2): 81-89.

Carvalho, P.E.R. 1994. Espécies florestais brasileiras: recomendações silviculturais, potencialidades e uso da madeira. Colombo, Empresa Brasileira de Pesquisa Agropecuária, Centro Nacional de Pesquisa de Florestas, PR.

Ferraz, D.K.; Artes, R.; Mantovani, W. \& Magalhães, L.M. 1999. Fenologia de árvores em fragmento de mata em São Paulo, SP. Revista Brasileira de Biologia 59(2): 305-317.

Fournier, L.A. 1974. Un método cuantitativo para la medición de características fenológicas en árboles. Turrialba 24(4): 422-423.

Fournier, L.A. 1976. Observaciones fenológicas em el bosque húmedo de premontano de San Pedro de Montes de Oca, Costa Rica. Turrialba 26(1): 54-59.

Frankie, G.W.; Baker, H.G. \& Opler, P.A. 1974. A comparative phenological studies of trees in tropical wet and dry forest in the lowlands of Costa Rica. Journal of Ecology 62(3): 881-919.

Gomez, P.F. \& Fournier, L.A. 1996. Fenología y ecofisiología de dos populaciones de Tabebuia rosea ("Roble de Sabana") en Costa Rica (Bignoniaceae). Revista de Biologia Tropical 44(1): 61-70.

Janzen, D.H. 1967. Synchronization of sexual reprodution of trees within the dry season in Central America. Evolution 21: 237-260.

Janzen, D.H. 1971. Seed predation by animals. Annual Review of Ecology and Systematics 2: 465-492.

Janzen, D.H. 1975. Ecologia vegetal nos trópicos. São Paulo, EPU e EDUSP.

Justiniano, M.A. \& Fredericksen, T.S. 2000. Phenology of Tree Species in Bolivian dry forests. Biotropica 32(2): 276-81.

Kageyama, P.Y. \& Gandara, F.B. 1998. Conseqüências genéticas da fragmentação sobre populações de espécies arbóreas. Série Técnica IPEF 12(32): 65-70.
Morellato, L.P.C.; Rodrigues, R.R.; Leitão Filho, H.F. \& Joly, C.A. 1989. Estudo comparativo da fenologia de espécies arbóreas de floresta de altitude e floresta mesófila semidecídua na serra do Japi, Jundiaí, São Paulo. Revista Brasileira de Botânica 12(1/2): 85-98.

Morellato, L.P.C. 1990. Estratégias fenológicas de espécies arbóreas em floresta de altitude na Serra do Japi, Jundiaí, São Paulo. Revista Brasileira de Botânica 50: 149-162.

Morellato, L.P.C. \& Leitão Filho, H.F. 1992. Padrões de frutificação e dispersão na Serra do Japi. Pp. 111-140. In: L.P.C. Morellato (coord.). História natural e preservação de uma área florestal no sudoeste do Brasil. Campinas, Editora da UNICAMP.

Morellato, L.P.C.; Talora, D.C.; Takahasi, A.; Bencke, C.S.C.; Romera, E.C. \& Zipparro, V. 2000. Phenology of Atlantic rain forest trees: a comparative study. Biotropica 26: 141-159.

Newstrom, L.E.; Frankie, G.W. \& Baker, H.G. 1994. A new classification for plant phenology based on flowering patterns in lowland tropical rain forest trees at La Selva, Costa Rica. Biotropica 26(2): 141-59.

Pedroni, F.; Maryland, S. \& Santos F.A.M. 2002. Fenologia da copaíba (Copaifera langsdorffii Desf. - Leguminosae, Caesalpinioideae) em uma floresta semidecídua no sudoeste do Brasil. Revista Brasileira de Botânica 25(2): 183-194.

Reich, P.B. \& Borchert, R. 1984. Water stress and tree phenology in tropical dry forest in the lowlands of Costa Rica. Journal of Ecology 72: 61-74.

Siegel, S. 1975. Estatística não paramétrica. Para as ciências do comportamento. São Paulo, Ed. McGraw Hill do Brasil Ltda.

Talora, D.C. \& Morellato, P.C. 2000. Fenologia de espécies arbóreas em floresta de planície litorânea do sudoeste do Brasil. Revista Brasileira de Botânica 23(1): 13-26.

van Shaick, C.P.; Terborgh, J.W. \& Wright, S.J. 1993. The phenology of tropical forest: adaptive significance and consequences for primary consumers. Annual Review of Ecology and Systematics 24: 353-377.

Wright, S.J. \& Van Shaick, C.P. 1994. Light and the phenology of tropical trees. American Naturalist 143(1): 192-199. 